\title{
CD56 and CD19 Antigens Expression in Acute Myeloid Leukemia Identifies Patients with Adverse Prognosis in Egypt
}

\author{
Running head: CD56 and CD19 antigens and Acute Myeloid Leukemia prognosis \\ Shereen El Shorbagy M.D. ${ }^{1}$, Rasha Haggag, M.D. ${ }^{2}$, Nashwa Alazizi, M.D. ${ }^{3}$, Tarek Abouzeid, M.D ${ }^{4}$ \\ ${ }^{1,2}$ Department of Medical Oncology , Faculty of Medicine, Zagazig University, Sharkia, Egypt \\ ${ }^{3}$ Department of Clinical Pathology, Faculty of Medicine, Zagazig University, Sharkia, Egypt \\ ${ }^{4}$ Department of Internal Medicine, Hematology unit, Mansoura University, Egypt
}

\begin{abstract}
CD56 was firstly described as a marker of natural killer cells and has been found expressed in several neoplasms including acute myeloid leukemias (AML), the presence of CD56 antigen on blast cells may influence complete remission and survival. CD19 is a $B$-lymphocyte marker, whose expression is associated with pediatric AML-M2 and the $t(8 ; 21)$ translocation. The biological and clinical significance of CD19 expression in AML is not clear. Patients and Methods: fifty de-novo AML were included, bone marrow aspirate subjected to immunophenotyping for lymphoid marker CD 19 and CD56, and cytogenetic study (karyotyping and FISH) and results were correlated with clinical outcome. Results: Fifty patients were included of which, 22 were male and 28 were female, with a median age of 40 years (16-75). There is a significant correlation between CD56 expression and cytogenetic abnormalities associated with unfavorable prognosis $(P=0.001)$, while the correlation between CD19 expression and cytogenetic analysis was not significant $(p=0.06)$. CD56\& CD19 expression did not influence CR rate $(P=0.51, p=0.08$; respectively). Expression of CD56\& CD19 had adverse effect on $D F S(p=0.03$ and $p<0.00$; respectively), and on $O S$ ( $p=0.001$ and $p=0.001$; respectively). Conclusion: CD56 and CD19 expression may identify acute myeloid leukemia patients with adverse prognosis.
\end{abstract}

Keywords: Acute Myeloid Leukemia; Immunophenotyping; CD56; CD19, prognosis.

\section{Introduction}

Acute myeloid leukemia (AML) could be considered as a heterogeneous group of disorders which often present with different morphological, immunophenotypic and cytogenetic patterns (1-3). Identification of these characteristics may be useful for a better prognostic evaluation and for a more appropriate therapeutic approach.

Occurrence of aberrant phenotype has been reported in acute leukemias with varying frequency though its prognostic importance remains controversial (1).

CD56 antigen, a 200-220 kDa cell surface glycoprotein, identified as an isoform of the neural adhesion molecules (NCAM)(4-6), it was firstly described as a marker of natural killer cells and subsequently, has also been found expressed in several lympho-hematopoietic neoplasms including acute myeloid leukemia (AML)(7-10). In fact, it has been previously reported that in AML patients with $\mathrm{t}(8 ; 21)$ (q22; $\mathrm{q} 22)$, generally considered at lower risk of relapse, the presence of CD56 antigen on blast cells may influence complete remission (CR) duration and survival (11), suggesting that CD56 expression could be useful in stratifying therapeutic approaches for this subtype of AML.(11,12).

CD19 is a phosphoglycoprotein lymphoid antigen which expressed normally on follicular dendritic cells\& B cells; it is commonly expressed in AML-M2 (13).
In order to better clarify the prognostic role of CD56\& CD19 expression in AML cells, we evaluated the presence of these antigens on leukemic cells of fifty newly diagnosed AML patients and results were correlated with the clinical outcome.

\section{Patients \& Method}

Fifty newly diagnosed adult AML cases presenting to Medical oncology, clinical pathology departments, Zagazig University, and Hematology unite, Internal medicine department, Mansoura University, Egypt,( between may, 2013 and may, 2014) were included in this study.

Before starting chemotherapy, adequate immunophenotype studies and, in the majority of patients, cytogenetic analyses were performed.

Complete blood count (CBC) was done using automated cell counter; Sysmex SF 3000(Roche-Diagnostics,Manheim, Germany). Bone marrow aspirates were examined for the presence of blast cells and the diagnosis of each leukemias subtype was established according to morphological, cytochemical and immunological criteria according to the French-American-British (FAB) and World Health Organization (WHO) classifications.

\section{Conventional karyotyping}

Culture: The BM cells(on heparin) were cultured in a medium \{RPMI 1640 supplemented with fetal calf serum (Gibco ,USA), L-glutamine (Gibco BRL) penicillin and 


\section{International Journal of Science and Research (IJSR) \\ ISSN (Online): 2319-7064 \\ Index Copernicus Value (2013): 6.14 | Impact Factor (2014): 5.611}

streptomycin, (Biochrom) incubated at $37 \mathrm{oC}$ in a strict sterile condition. three cultures tubes were used for each patient and should be kept for 24,48 and 72 hours.

Harvesting: using colcemid $50 \mathrm{ul}\{10 \mu \mathrm{g} / \mathrm{ml}$ (Gibco BRL) $\}$ for 20 minutes then $10 \mathrm{ml}$ hypotonic solution were added (potassium chloride $(5.59 \mathrm{~g} / \mathrm{L})$ ) for 30 minutes at $37 \mathrm{c}$ Fixation: $10 \mathrm{ml}$ fixative solution( absolute methanol (3 parts) mixed with glacial acetic acid (1 part))were added and left for 10minutes this step was repeated twice then the pellet was kept at fridge overnight. Chromosome Spreading: 3-4 drops of cells suspended in fixative were allowed to fall on a cold pre-cleaned glass slide from a height of about $40-60 \mathrm{~cm}$ to obtain good cell spread GBanding: after aging of cells for 48 hours at room temperature banding were done using trypsin solution (Gibco ,USA) (Seabright, 1971).

At least 20 metaphases were examined; an automated karyotyping system was used for analysis (IMSTAR, France) Karyotyping was done according to the International System for Human Cytogenetic Nomenclature (ISCN, 2005, Karger) .

\section{Fluorescence in situ hybridization}

FISH assays were performed by following the probe manufacturer instructions $\quad\{\mathrm{t}(8 ; 21) \quad(\mathrm{q} 22 ; \mathrm{q} 22)$ RUNX1/RUNX1T1,inv(16)(p13.1q22)CBFB/MYH11, and $\mathrm{t}(15 ; 17)(\mathrm{q} 22 ; \mathrm{q} 12) \mathrm{PML} / \mathrm{RARA}$ dual fusion coulor aquarius, Cytocell., , UK\}

The slides were analyzed using an epifluorescence microscope (Olympus, BX63) and a computerized image analyzer cytovision software(Applied imging,Genetix Europe) A minimum of 200 cells per specimen/probe were scored

For Immunophenotyping, bone marrow cells were stained with various combinations of fluorescein isothiocyanate (FITC), phycoerythrin (PE), peridin-clorophyll protein (PerCP) -labeled monoclonal antibodies against the following antigens: CD3,CD5,CD13,CD14,CD19,CD20,CD34,CD41 and CD45 (BD, Biosciences, San Jose, CA), CD7,CD22, CD33, CD64,glycophorinA and CD10 (Dako), other antibodies were used to identify cytoplasmic antigens as a triple color MPO, CD3, CD79a (BD) and nuclear terminal deoxynucleotidyl transferase (TdT) (Dako).

Cell surface immunophenotyping was performed for CD56 and CD19 on blast cells in acute myeloid leukemia. CD56 (PerCP) CD19 (FITC) were obtained from R\&D system (Minneapolis, USA). Gaiting on myoblasts was based on CD45 versus side scatter analysis and a co-expression of CD56 and CD19 on myeloblast was detected.

\section{Statistical Analysis}

Disease free survival (DFS) was calculated from time of complete remission (CR) till relapse or last follow up to, and overall survival (OS) was calculated from diagnosis till death or last follow up. Survival was plotted with Kaplan-
Meier curves, and the data for the various groups were compared with a log-rank test. Multivariate analysis was performed by Cox model after the proportional hazard assumption was checked. $\mathrm{P}$ value less than 0.05 was considered to be statistically significant.

\section{Results}

The baseline characteristics of the 50 patients who were included in the study are summarized in Table (1). Fifty denovo AML patients were included of which, 22 were male and 28 were female, with a median age of 40 years (16-75). All patients under 65 years underwent the same chemotherapy protocol consisting of first-line induction and consolidation regimens. First-line induction regimen comprised a 7-day continuous infusion of standard-dose cytosine arabinoside $(100 \mathrm{mg} / \mathrm{m} 2)$ and doxorubicin (30 $\mathrm{mg} / \mathrm{m} 2$ ) for 3 days (3-7 protocol). The consolidation treatment included the administration of high-dose cytosine arabinoside $(1 \mathrm{~g} / \mathrm{m} 2$, daily, days $1-5)$. Patients more than 65 years old had reduced drug doses and 3 out of 50 evaluable patients underwent allogeneic bone marrow transplantation within 6 months after achieving CR.

Thirteen patients presented with pallor, 30 with fever, 16 with purpura and 3 patients presented with organomegally. According to $\mathrm{FAB}$ criteria, patients were classified into 5 as M1, 14 as M2, 6 as M3, 9 as M4, 11 as M5 and 2 as M6 and 3 as Mixed Phenotype Acute Leukemia (MPAL).

\section{Correlation between CD56 \& CD19 expression with immunophenotype and cytogenetic analysis:}

CD56 was expressed on $21 / 50$ cases (38\%), when correlated with FAB criteria, CD56 expression, was detected in 3/5(60\%) M1, 6/14 M2, 0/6 M3, 4/9(44\%) M4, 6/11(55\%) M5, 0/2 M6 and 2/3(67\%) in mixed lineage acute leukemia $(\mathrm{p}=0.2)$.

Cytogenetic analysis was available only in 40 out of 50 patients, 15 of whom were CD56+ and 25 were CD56-, the cytogenetic studies were failed culture in 10 patients, CD56 expression was positive in 11/16 (69\%) unfavorable cytogenetic, and negative in all favorable cytogenetic cases, so CD56 was significantly expressed in patients with unfavorable cytogenetic abnormalities $(\mathrm{P}=0.001)$.

CD19 was expressed on 17/50 (34\%) cases, 2 as FAB M1, 5 cases were FAB M2, one case was FAB M3, 3 as M4, 4 as M5 and 2 cases for MPAL ( $\mathrm{p}=0.67)$.

CD19 was positive in 9/16(56\%) of unfavorable cytogenetics, and positive only in $1 / 7$ (19\%) of favorable cytogenetics, so there is no significant correlation between CD19 expression and cytogenetic analysis $(\mathrm{p}=0.06)$.

\section{Correlation of CD56 \& CD19 expression with clinical outcome}

To address the hypothesis of whether CD56\& CD19 expression could represent as adverse prognostic factors in AML, their presence were correlated with clinical response. The response was evaluated after induction therapy. The 


\section{International Journal of Science and Research (IJSR) \\ ISSN (Online): 2319-7064}

Index Copernicus Value (2013): 6.14 | Impact Factor (2014): 5.611

overall $\mathrm{CR}$ rate in our series of patients was 74\%. However, among CD56- patients, CR was achieved in $21 /$ 29 patients $(72.4 \%)$, and in 16 out of $21(76.2 \%)$ of CD56+ cases $(\mathrm{P}=0.51)$. Overall, CD56 positivity did not influence $\mathrm{CR}$ rate.

Also in CD $19+$ cases, CR was achieved in 10 patients (58.8\%), while in CD19- cases CR was achieved in 27 $(81.8 \%)$ patients $(\mathrm{p}=0.08)$.

After a median follow up 15 months, Median DFS was not reached, while mean DFS of all patients was 13.9 months. In CD56+ cases, mean DFS was 11 vs. 16 months in CD56- cases. Also in CD19 + cases, mean DFS was 8 vs. 16 months in CD19- cases. So expression of CD 56, CD19 have adverse effect on DFS $(p=0.003$ and $p<0.001$; respectively) (Figure 1, 2).

Death occurred in $26 \%$ of the patients $(13 / 50)$, median OS was not reached, while mean OS was 22.9 months. Mean OS of patients with CD56+ was 15 vs. 27 months in CD56 - cases $(p=0.001)$. In CD19 + cases, the mean OS was 10.9 months while it was 26.4 months in CD19- cases ( $p=0.001$ ), so patients with expression of CD $56, C D 19$ have worse OS (Figure 3, 4).

Co-expression of both CD56 and CD19 marker was detected in 11 cases $(22 \%)$, 9 of them had unfavorable cytogenetics; the other 2 had failed cytogenetic $(\mathrm{p}<0.001)$ also Co-expression of both CD56 and CD19 genes had a significant adverse effect on DFS and OS ( $p<0.001$, and $\mathrm{p}<0.001$; respectively; figure 5,6 ).

Impact of prognostic factors on Disease-free survival and Over- all survival by univariate and multivariate analysis was shown in table (2).

Table 1: Shows patients characteristics:

\begin{tabular}{|l|l|l|}
\hline Patients characteristics & \multicolumn{1}{|c|}{ NO } & Percentage \\
\hline Age: & & \\
$\leq 60$ years & 45 & $90 \%$ \\
$>60$ years & 5 & $10 \%$ \\
\hline Sex: & & \\
Male & 22 & $44 \%$ \\
Female & 28 & $56 \%$ \\
\hline FAB Classification: & & \\
M1 & 5 & $10 \%$ \\
M2 & 14 & $28 \%$ \\
M3 & 6 & $12 \%$ \\
M4 & 9 & $18 \%$ \\
M5 & 11 & $22 \%$ \\
M6 & 2 & $4 \% 6$ \\
Mixed lineage & 3 & $6 \%$ \\
\hline Cytogenetic: & & \\
Favorable & 7 & $14 \%$ \\
Intermediate & 17 & $34 \%$ \\
unfavorable & 16 & $32 \%$ \\
failed & 10 & $20 \%$ \\
\hline Presentation & & \\
Pallor & 13 & $26 \%$ \\
Fever & 30 & $60 \%$ \\
\hline
\end{tabular}

\begin{tabular}{|l|l|l|}
\hline $\begin{array}{l}\text { Purpura } \\
\text { organomegally }\end{array}$ & 16 & $\begin{array}{l}32 \% \\
6 \%\end{array}$ \\
\hline Response to treatment: & 3 & \\
CR & 37 & $74 \%$ \\
Not CR & 13 & $26 \%$ \\
\hline
\end{tabular}

Table 2: Impact of prognostic factors on Disease-free survival and Over- all survival.

\begin{tabular}{|c|c|c|c|c|}
\hline \multicolumn{5}{|c|}{ DFS } \\
\hline \multirow[t]{2}{*}{ Prognostic Factor } & \multirow{2}{*}{$\begin{array}{l}\text { Univariate } \\
\text { analysis }\end{array}$} & \multicolumn{3}{|c|}{ Multivariate analysis } \\
\hline & & HR & $95 \% \mathrm{CI}$ & $\mathrm{P}$ \\
\hline Age & 0.23 & 0.2 & $0.4-2.4$ & 0.19 \\
\hline WBCs & 0.59 & 0.7 & $0.3-2$ & 0.6 \\
\hline Cytogenetics risk & 0.11 & 0.4 & $0.17-1.4$ & 0.2 \\
\hline CD 56 & 0.03 & 0.26 & $0.09-0.68$ & 0.006 \\
\hline CD19 & $<0.001$ & 0.14 & $0.0-0.41$ & $<0.001$ \\
\hline $\begin{array}{c}\text { Co expression of CD56 } \\
\text { and CD19 }\end{array}$ & $<0.001$ & 0.06 & $0.015-0.255$ & $<0.001$ \\
\hline \multicolumn{5}{|c|}{ OS } \\
\hline \multirow[t]{2}{*}{ Prognostic Factor } & \multirow{2}{*}{$\begin{array}{l}\text { Univariate } \\
\text { analysis }\end{array}$} & \multicolumn{3}{|c|}{ Multivariate analysis } \\
\hline & & HR & $95 \% \mathrm{CI}$ & $\mathrm{P}$ \\
\hline AGE & 0.6 & 3.3 & $0.2-53.7$ & 0.3 \\
\hline WBCs & 0.4 & 1.18 & $0.3-3.7$ & 0.7 \\
\hline Response to treatment & 0.15 & 2.5 & $0.7-6.9$ & 0.15 \\
\hline Cytogenetics risk & 0.18 & 0.2 & $0.4-2.8$ & 0.2 \\
\hline CD56 & $<0.001$ & 0.4 & $0.05-3.4$ & 0.2 \\
\hline CD19 & $<0.001$ & 0.26 & $0.07-2.8$ & 0.2 \\
\hline $\begin{array}{c}\text { Co expression of CD56 } \\
\text { and CD19 }\end{array}$ & $<0.001$ & 0.17 & $0.05-0.5$ & 0.003 \\
\hline
\end{tabular}

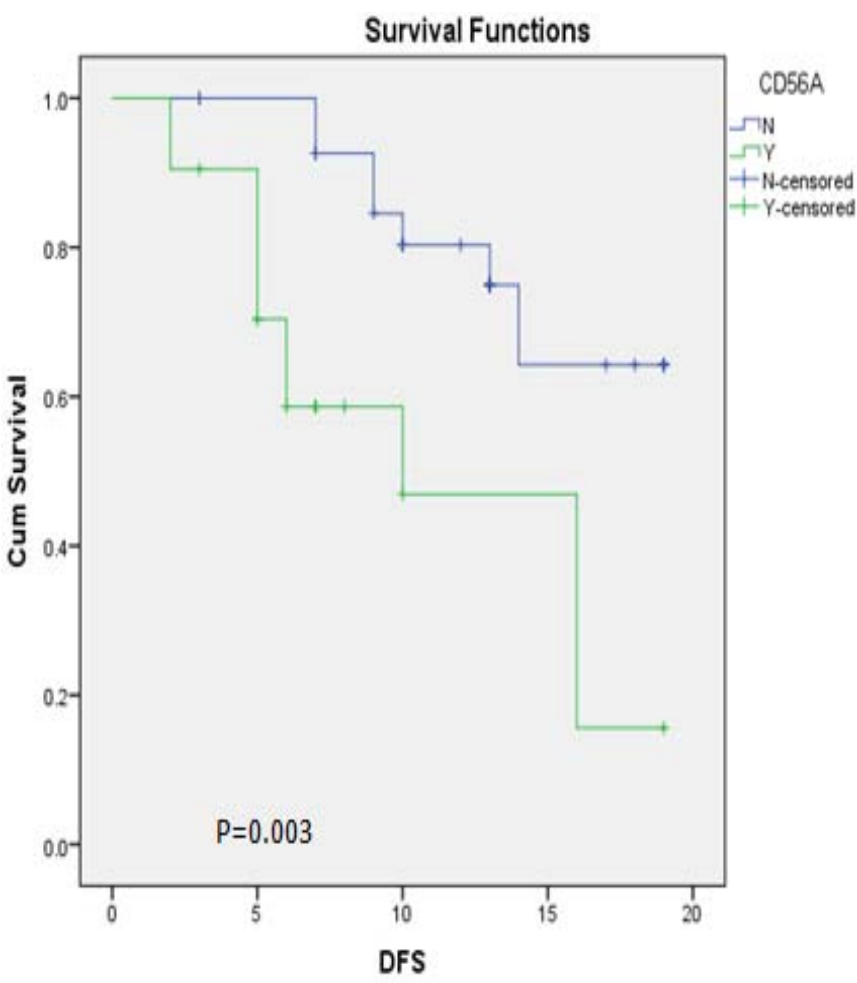

Figure 1: Correlation between CD56 expression and DFS 
International Journal of Science and Research (IJSR)

ISSN (Online): 2319-7064

Index Copernicus Value (2013): 6.14 | Impact Factor (2014): 5.611

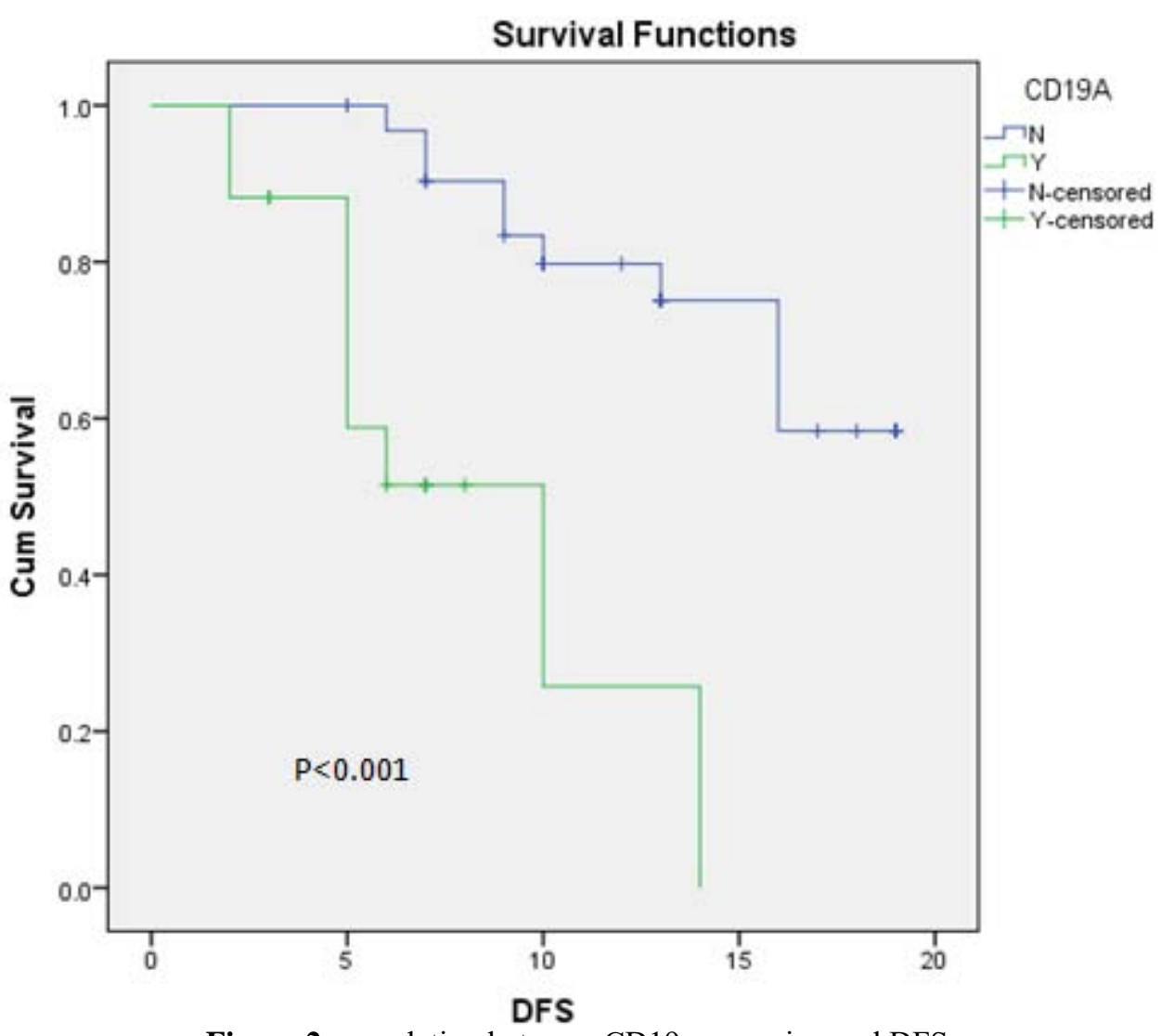

Figure 2: correlation between CD19 expression and DFS

Survival Functions

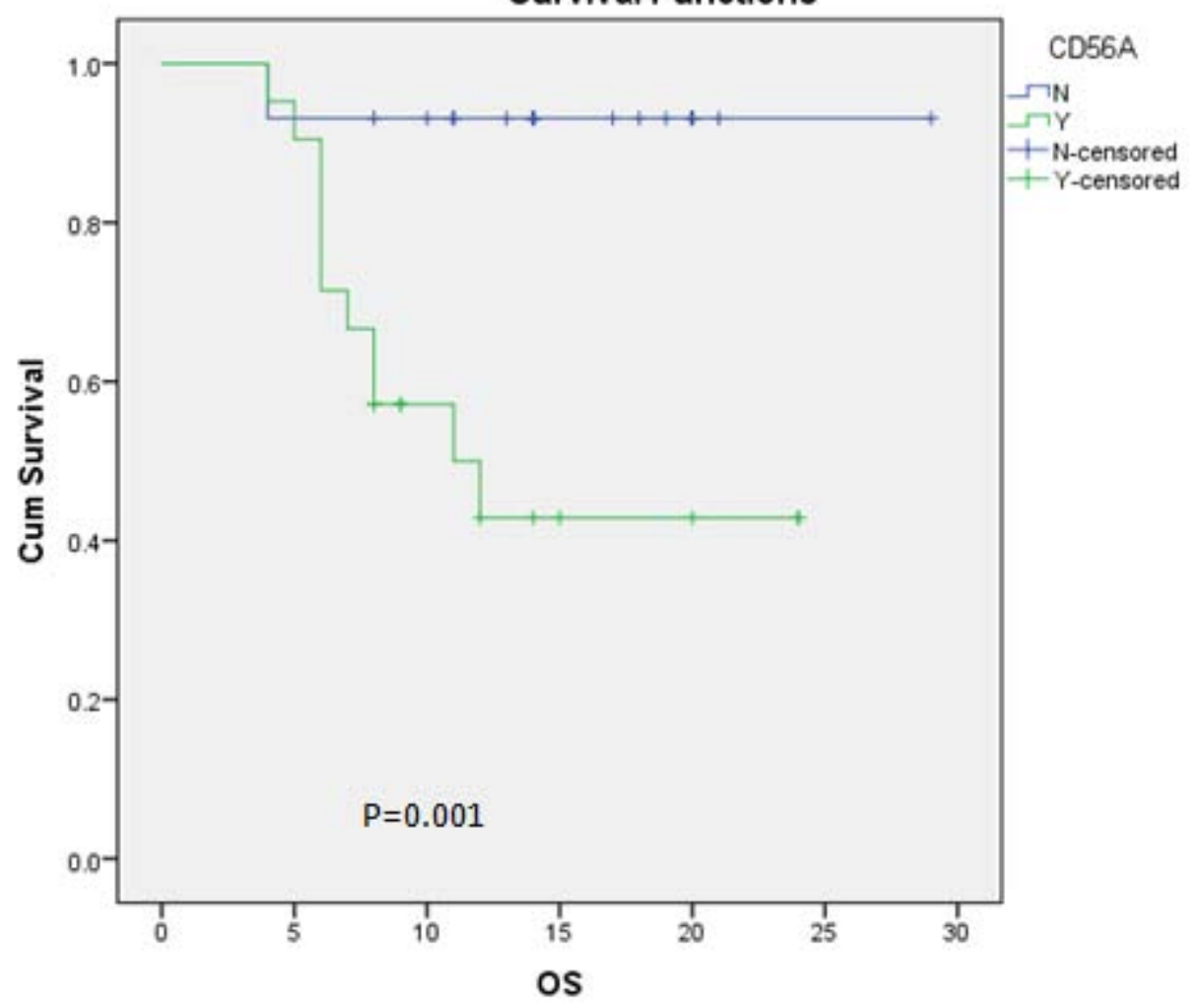

Figure 3: correlation between CD56 expression and OS

Volume 5 Issue 1, January 2016

www.ijsr.net 
International Journal of Science and Research (IJSR)

ISSN (Online): 2319-7064

Index Copernicus Value (2013): 6.14 | Impact Factor (2014): 5.611

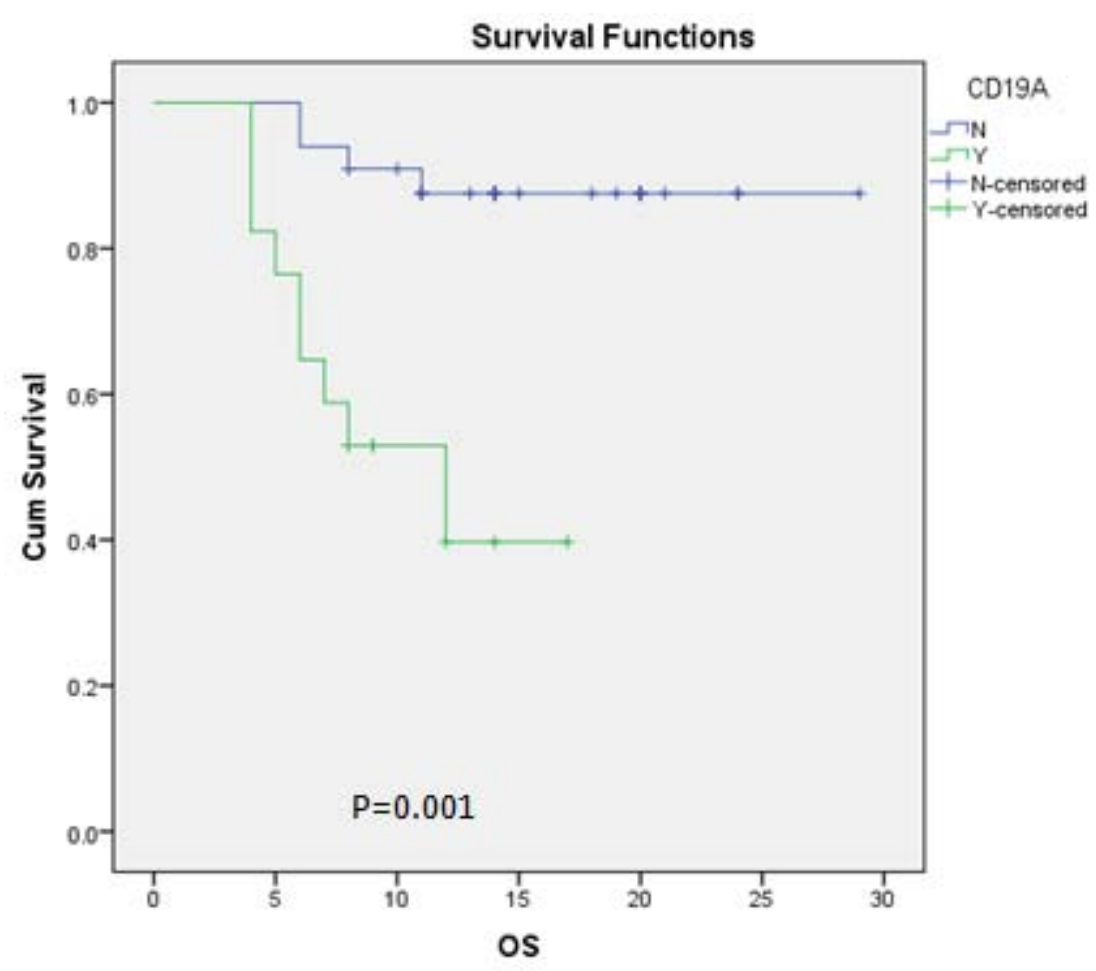

Figure 4: correlation between CD19 expression and overall survival

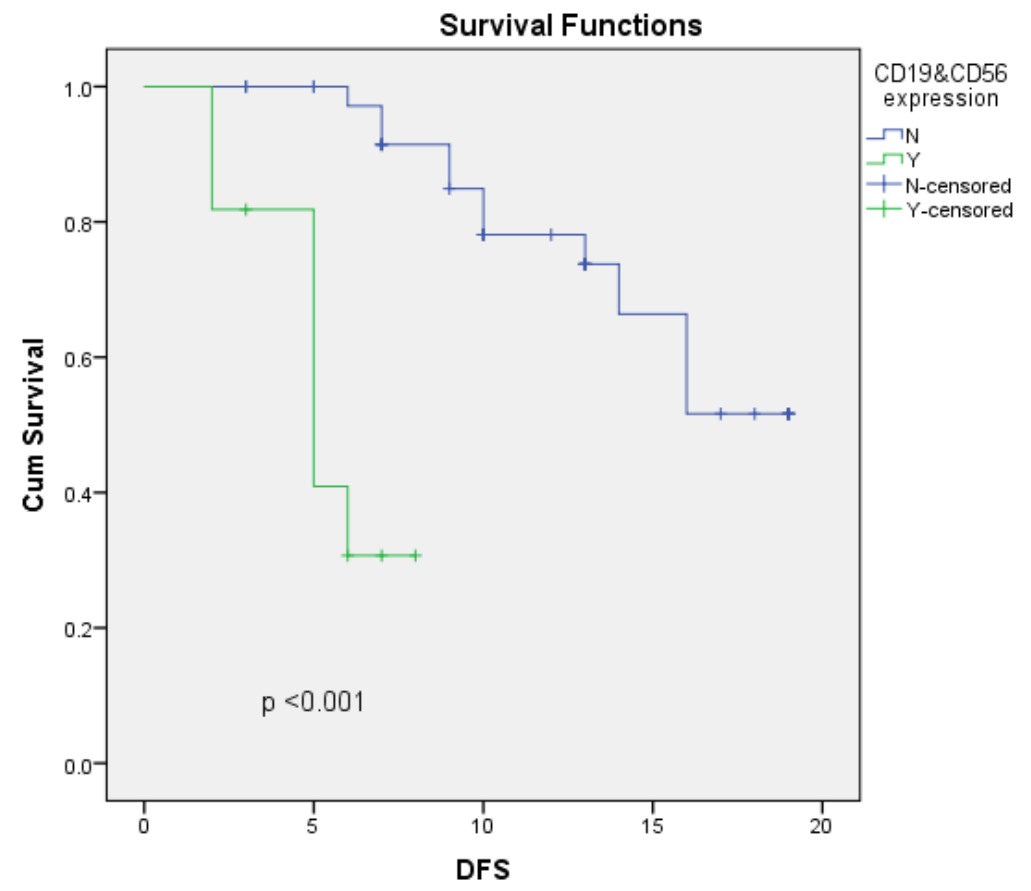

Figure 5: correlation between co expression of both CD56\& CD19 and DFS

Volume 5 Issue 1, January 2016

www.ijsr.net 
International Journal of Science and Research (IJSR)

ISSN (Online): 2319-7064

Index Copernicus Value (2013): 6.14 | Impact Factor (2014): 5.611

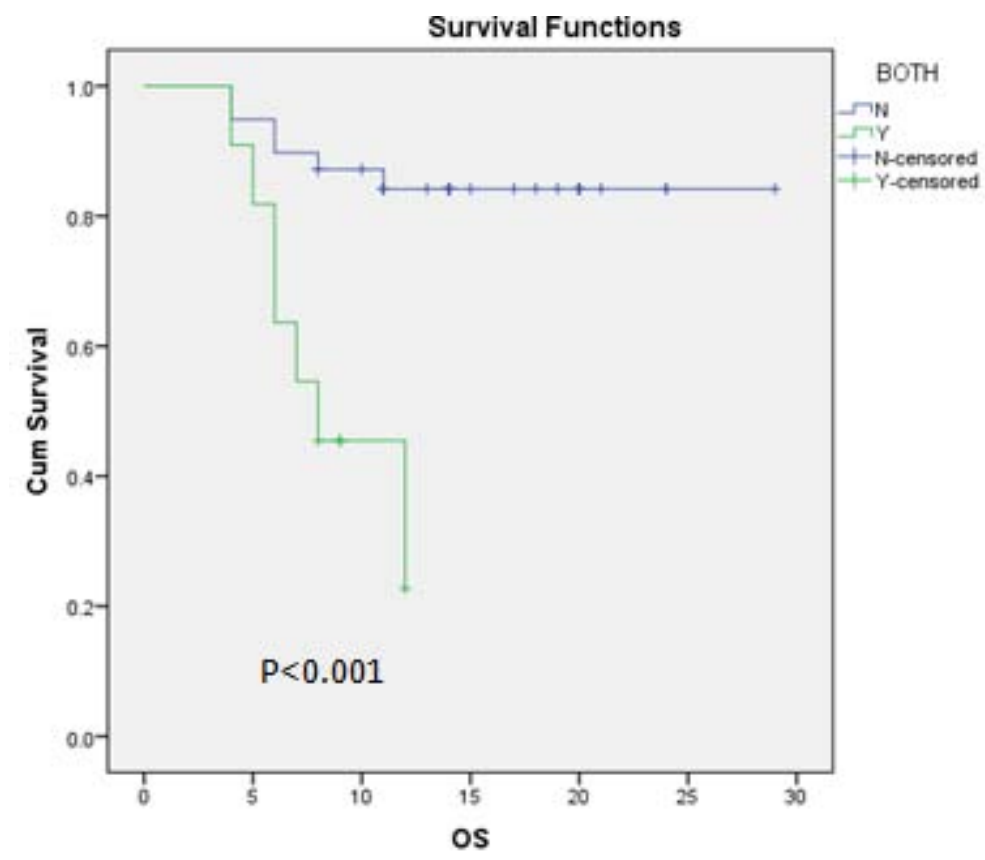

Figure 6: correlation between co expression of both CD56\& CD19 and overall survival

\section{Discussion}

Several studies reported the correlation between myeloid blast cell immunophenotypic, morphology, cytogenetic pattern and patient's clinical outcome (14-16). For example, lymphoid-associated antigens such as CD19 has been considered an adverse prognostic factor for AML patients (17-19).Recently, many studies have addressed the role of CD56 expression in hematological malignancies. In fact, this antigen is an isoform of the neural adhesion molecules (NCAM), has been recorded in several myeloproliferative disorders including acute leukemias (20-25). In this latter setting, CD56 expression was frequently associated with a poorer outcome (25), in AML patients with $\mathrm{t}(8 ; 21)(\mathrm{q} 22 ; \mathrm{q} 22)$ and in APL cases, which are considered AML with good prognosis, the presence of CD56 antigen on the membrane of leukemic blasts led to a significant reduction of $\mathrm{CR}$ and overall survival duration (25-27).

In our study CD56 was expressed in $38 \%$ of cases, and seen in all FAB types except M3 and M6. However highest frequency was seen in MPALtype, while Raspadori D et al (28), reported that CD56 antigen was detected in only $24 \%$ of cases and CD56 antigen was rarely expressed in M0 patients, but was more frequently expressed in M2 and M5 cases.

Also in our study CD 19 was expressed in $34 \%$ of cases and not limited to M2 but it was seen in M1, M3and M4 and showed highest expression in MPAL (66.6\%). While, in a study from Taiwan (29), CD19 expression was only observed in AML-M2 (5/36, 14\%), Zheng J et al and Bahia $\mathrm{DM}$ et al $(30,31)$ also found that $\mathrm{CD} 19$ was expressed at highest rate in AML M2.

In concordance with our results, Jha $\mathrm{R}$ et al (32) observed that CD 19 was not limited to M2 but showed highest expression in M0 (15.6\%).
Among 6 cases of FAB M3 morphology with $t(15 ; 17)$ included in our study, 1 case had CD19+ antigen but no cases expressed CD56, and this also found in EL-SISSY A et al (33), who reported that among 6 cases of FAB M3 morphology included in his study, 3 cases expressed lymphatic antigens, but in contrast to our study, Wang et al (34), reported that no co expression of lymphoid antigens was detected among $7 \mathrm{M} 3$ cases with $\mathrm{t}(15 ; 17)$.

Cytogenetic analysis was available only in 40 out of 50 of our patients, and there was a significant correlation between CD56, CD19 expression and cytogenetic abnormalities associated with unfavorable prognosis $(\mathrm{P}=0.001, \mathrm{p}=0.006$ respectively), and this result was matched with those reported by Raspadori $\mathrm{D}$ et al.(28), where a cytogenetic analysis was evaluable only in 132 out of 152 patients, a significant correlation between CD56 expression and cytogenetic abnormalities associated with unfavorable prognosis was documented both in univariate and multivariate analysis $(\mathrm{P}=$ 0.008 and 0.025 , respectively) .

The clinical relevance of lymphoid antigen expression (LY+) in AML has been highly controversial. Some studies have reported LY+ AML to be associated with the poor prognosis (35-37), but some reported it to be associated with favorable prognosis (38), whereas other suggest it to be of no prognostic value (30).

In our study, CD56 positivity did not influence CR rate $(\mathrm{p}=0.51)$. This may be due to small sample size. In CD $19+$ cases, CR was achieved in $58.8 \%$ of patients, while in CD19cases CR was achieved in $81.8 \%$ of patients $(p=0.08)$, and this result was matched with those reported by Jiang NG et al(39), where 91 cases of AML were included, and they found 14 cases of AML only expressed CD19, 10 cases expressed CD56, also they reported that CR ratio and DFS were lower in patients expressed both lymphatic markers, DFS of CD56+ AML patients was lower, but CR ratio had no significant difference compared with CD56- patients. 


\section{International Journal of Science and Research (IJSR) \\ ISSN (Online): 2319-7064}

Index Copernicus Value (2013): 6.14 | Impact Factor (2014): 5.611

In our study, patients with expression of CD 56 and CD19 had worse OS and DFS ( $p=0.001 ; p=0.001$ and $p=0.03$; $\mathrm{p}=0.00$; respectively).

Co-expression of both CD56 and CD19 which was detected in $(22 \%)$ of our cases had have adverse effect on DFS and OS by univariate and multivariate analysis.

In adverse to our results, Noriyoshi Iriyama et al (40), who investigated 144 patients with AML with $\mathrm{t}(8 ; 21)$. CD19 expression was (36\%), and CD56 expression was (65\%). CD19 expression is significantly correlated with improved prognosis in his study population, probably because the CD56-negative population frequently demonstrates CD19 positivity.

In conclusion, our data suggest that CD56, CD19 antigenic expression in AML patients is more frequently associated with unfavorable cytogenetic abnormalities. Moreover, they correlate with a reduced probability of achieving CR and with a shorter survival, and therefore, the presence of CD56, CD19 antigens on myeloid blasts should be regularly assessed in AML patients at diagnosis, and should be taken into consideration in designing future therapeutic strategies based on patient-specific risk factors.

Conflict of interest: the authors indicated no potential conflict of interest

The authors indicated no sources of support in the form of grants, equipment or drugs

\section{Publication Type: Original research}

\section{Refrences}

[1] McCulloch EA, Kellecher CA, Miyauchi J, Wang C, Cheng GYN, Minden MD, Curtis JE. Heterogeneity in acute myeloblastic leukemia. Leukemia 1998; 2: 38s.

[2] Bennet JM, Catovsky D, Daniel MT, Flandrin G, Galton DAG, Gralnick HR, Sultan C. Proposals for the classification of acute myeloid leukemias. $\mathrm{Br} \mathrm{J}$ Haematol 1976; 33: 451-458.

[3] Legrand O, Perrot JY, Baudard $M$ et al. The immunophenotype of 177 adults with acute myeloid leukemia: proposal of a prognostic score. Blood 2000;96:870-7.

[4] Lanier LL, Le AM, Civin CI, Loken MR, Phillips JH. The relationship of CD16 (Leu11) and Leu19 (NKH-1) antigen expression of human peripheral blood NK cells and cytotoxic lymphocytes. J Immunol 1986; 136: 4480-4483.

[5] Griffin JD, Hercend T, Beveridge R, Schlossmann SF. Characterization of an antigen expressed by human natural killer cells. J Immunol 1983; 130: 2947-2951.

[6] Lanier LL, Testi R, Bindi J, Phillips JH. Identity of Leu-19 (CD56) leukocyte differentiation antigen and neural cell adhesion molecule. J Exp Med 1989; 169: 2233-2238

[7] Savoia P, Fierro MT, Novelli M, Quaglino P, Verrone A, Geuna M, Bernengo MG. CD56-positive cutaneous lymphoma: a poorly recognized entity in the spectrum of primary cutaneous disease. Br J Dermatol 1997; 137: 966-971.

[8] Muroi K, Omine K, Kuribara R, Uchida M, Izumi T, Hatake K, Miura Y. CD56 expression in B-cell lymphoma. Leuk Res 1998; 22: 201-202.

[9] Ikushima S, Yoshihara T, Misawa S, Morioka Y, Hibi S, Imashuku S. Expression of CD56/NCAM on hematopoietic malignant cells. Auseful marker for acute monocytic and megakaryocytic leukemias. Int $\mathrm{J}$ Haematol 1991; 54: 395-403.

[10] Seymour JF, Pierce SA, Kantarjian HM, Keating MJ, Estey EH. Investigation of karyotypic, morphologic and clinical features in patients with acute myeloid leukemia blast cells expressing the neural cell adhesion molecule (CD56). Leukemia 1994; 8: 823-826.

[11] Baer Mr, Stewart CC, Lawrence D, Arthur DC, Byrd JC, Davey FR, Schiffer CA, Bloomfield CD. Expression of the neural cell adhesion molecule CD56 is associated with short remission duration and survival in acute myeloid leukemia with $\mathrm{t}(8 ; 21)$ (q22;q22). Blood 1997; 90: 1643-1648.

[12] Daniels JT, Davis BJ, Houde-McGrail L, Byrd JC. Clonal selection of CD56+ $\mathrm{t}(8 ; 21)$ AML blasts: further suggestion of the adverse clinical significance of this biological marker? Br J Haematol 1999; 107: 371-383.

[13]Loken MR, Van de Loosdrecht A, Ogata K, Orfao A. Flow cytometry in myelodysplastic syndrome : report from a working conference. Leukemia research 2008; 32, 5-17.

[14] Drexler HG. Classification of acute myeloid leukemia. Acom parison of FAB and immunophenotyping. Leukemia 1987; 1: 697-705.

[15] Dastugue N, Payen C, Lafage-Pochitaloff M, Bernard P, Leroux D, Huguet-Rigal F, Stoppa AM, Marit G, Molina L, Michallet M, Maraninchi D, Attal M, Reiffers J. Prognostic significance of karyotype in de novo adult acute myeloid leukemia. Leukemia 1995; 9: 1491-1498.

[16] Baer MR, Stewart CC, Lawrence D, Arthur DC, Mrozek K, Strout MP, Davey FR, Schiffer CA, Bloomfield CD. Acute myeloid leukemiawith 11q23 translocations: myelomonocytic immunophenotypeby multiparameter flow cytometry. Leukemia 1998; 12: 317-325.

[17] Kita K, Miwa H, Nakase K, Kawakami K, Kobayashi T, ShirakawaS, Tanaka I, Otha C, Tsutani H, Oguma S. Clinical importance ofCD7 expression in acute myelocytic leukemia. Blood 1993; 81:2399-2405.

[18]Del Poeta G, Stasi R, Venditti A, Suppo G, Aronica G, Bruno A,Masi M, Tabilio A, Papa G. Prognostic value of cell marker analysisin de novo acute myeloid leukemia. Leukemia 1994; 8:288-394.

[19] Suzuki R, Yamamoto K, Seto M, Kagami Y, Ogura M, Yatabe Y, Suchi T, Kodera Y, Morisima Y, Takagashi T, Saito H, Ueda R, Nakamura S. CD7+ and CD56+ myeloid/natural killer cell precursor acute leukemia: a distinct hematolymphoid disease entity. Blood 1997; 90: 2417-2428

[20] Hatano Y, Miura I, Horiuchi T, Hoshi N, Nanjou H, Masuda H, Miura AB. Cerebellar myeloblastoma formation in CD7-positive, neural cell adhesion molecule (CD56)-positive acute myelogenous leukemia (M1). Ann Hematol 1997; 75: 125-128.

[21] Murase T, Suzuki R, Tashiro K, Moishima Y, Nakamura S. Blast crisis of chronic myelogenous leukemia 


\section{International Journal of Science and Research (IJSR) \\ ISSN (Online): 2319-7064}

Index Copernicus Value (2013): 6.14 | Impact Factor (2014): 5.611

exhibiting immunophenotypic features of a myeloid/natural killer cell precursor. Int $\mathrm{J}$ Hematol 1999; 69: 89-91.

[22] Reuss-Borst MA, Steinke B, Waller HD, Buhring HJ, Muller CA. Phenotypic and clinical heterogeneity of CD56-positive acute nonlymphoblastic leukemia. Ann Haematol 1992; 64: 78-82.

[23] Dunphy $\mathrm{CH}$, Gregowicz AJ, Rodriguez G. Natural killer cell acute leukemia with myeloid antigen expression. Apreviously undescribed form of acute leukemia. Hematopathology 1995; 104: 212-215.

[24] Baer Mr, Stewart CC, Lawrence D, Arthur DC, Byrd JC, Davey FR, Schiffer CA, Bloomfield CD. Expression of the neural cell adhesion molecule CD56 is associated with short remission duration and survival in acute myeloid leukemia with $\mathrm{t}(8 ; 21)$ (q22;q22). Blood 1997; 90: 1643-1648.

[25] Daniels JT, Davis BJ, Houde-McGrail L, Byrd JC. Clonal selection of CD56+t $(8 ; 21)$ AML blasts: further suggestion of the adverse clinical significance of this biological marker? Br J Haematol 1999; 107: 371-383.

[26] Murray CK, Estey E, Paietta E, Howard RS, Edenfield W J, Pierce S, Mann KP, Bolan C, Byrd JC. CD56 expression in acute promyelocytic leukemia: a possible indicator of poor treatment outcome? J Clin Oncol 1999; 17: 293-297.

[27] Raspadori D, Lauria F, Ventura MA, Rondelli D, Visani G, de Vivo A, Tura S. Incidence and prognostic relevance of CD34 expression in acute myeloblastic leukemia: analysis in 141 cases. Leuk Res 1997; 21: 603-607

[28] Chen SW, Li CF, Chuang SS et al. Aberrant coexpression of CD19 and CD56 as surrogate markers of acute myeloid leukemias with $\mathrm{t}(8 ; 21)$ in Taiwan International Journal of Laboratory Hematology 2008;30:133-8.

[29]Zheng J, Wang X, Hu Y et al. A correlation study of immunophenotypic, cytogenetic, and clinical features of 180 AML patients in China. Cytometry B Clin Cytom 2008;74:25-9.

[30]Bahia DM, Yamamoto M, Chauffaille Mde L et al. Aberrant phenotypes in acute myeloid leukemia: a highf requency and its clinical significance. Haematologica. 2001;86:801-6.

[31] Jha R1, Grover G2, Bose P3. Lymphoid associated antigen expression in new cases of Acute Myeloid Leukemia. Journal of Pathology of Nepal (2013) Vol. 3, 487-490.

[32]EL-SISSY AH, EL-MASHARI MA, BASSUNI W Y and EL-SWAAYED A F. Aberrant Lymphoid Antigen Expression in Acute Myeloid Leukemia in Saudi Arabia. Journal of the Egyptian Nat. Cancer Inst., Vol. 18, No. 3, September: 244-249, 2006.

[33] Wang XB, Zheng JE, Gu JX, Yao JX, Yang J, Liu J, et al. Correlation of immunophenotype to cytogenetics and clinical features of adult acute myeloid leukemia. Ai Zheng. 2005, 24 (6): 667-71.

[34] Smith LJ, Curtis JE, Messner HA, Senn JS, Furthmayr $\mathrm{H}$, McCulloch EA .Lineage infidelity in acute leukemia. Blood 1983;61:1138-45.

[35] Cross AH, Goorha RM, Nuss R et al. Acute myeloid leukemia with T-lymphoid features: a distinct biologic and clinical entity. Blood 1988;72:579-87.
[36] Ball ED, Davis RB, Griffin JD et al. Prognostic value of lymphocyte surface markers in acute myeloid leukemia. Blood 1991;77:2242-50.

[37]Drexler HG, Thiel E, Ludwig WD .Acute myeloid leukemias expressing lymphoid-associated antigens: diagnostic incidence and prognostic significance. Leukemia 1993;7:489-98.

[38]Jiang NG, Chen XM, Zhong L, Zeng TT. Immunophenotype charactresics and prognosis of acute leukemia patients with cross expressing lymphoid and myeloid lineage associated antigens. Zhongguo Shi yan Xue Ye Xue Za Zhi. 2010 Dec;18(6):1405-9.

[39] Noriyoshi Iriyamaa, Yoshihiro Hattaa, Jin Takeuchia, Yoshiaki Ogawab. CD56 expression is an independent prognostic factor for relapse in acute myeloid leukemia with $\mathrm{t}(8 ; 21) .2013 \mathrm{JUNE}$, Leukemia Research , 05.002 